\title{
Effects of Antidepressants on Weight and on the Plasma Levels of Leptin, TNF- $\alpha$ and Soluble TNF Receptors: A Longitudinal Study in Patients Treated with Amitriptyline or Paroxetine
}

\author{
Dunja Hinze-Selch, M.D., Andreas Schuld, M.D., Thomas Kraus, M.D., Martin Kühn, M.D., \\ Manfred Uhr, M.D., Monika Haack, M.A., and Thomas Pollmächer, M.D.
}

Leptin, tumor necrosis factor- $\alpha$ (TNF- $\alpha$ ), and soluble TNF receptors are involved in weight regulation. Antipsychotic agents, such as clozapine, induce weight gain and increase circulating levels of these cytokines. To assess whether obesityinducing antidepressants have a similar effect, we measured plasma cytokine levels in depressive inpatients during the first six weeks of treatment with tricyclic agents (amitriptyline or nortriptyline, $\mathrm{n}=12)$, with paroxetine $(\mathrm{n}=10)$, or without medication $(\mathrm{n}=14)$. There was an increase in the body mass index at week 6 of treatment with the tricyclics, which was preceded by a significant increase in soluble TNF receptor $p 75$ plasma levels. Circulating levels of leptin were not affected. Paroxetine and drug-free treatment did not affect any of these parameters. We conclude that weight gain induced by psychotropic agents may occur without increased circulating levels of leptin. However, activation of the TNF- $\alpha$ system might be an early and sensitive marker of ensuing weight gain. [Neuropsychopharmacology 23:13-19, 2000] (C) 2000 American College of Neuropsychopharmacology. Published by Elsevier Science Inc. All rights reserved
KEY WORDS: Soluble TNF receptors; Leptin; Body mass index; Tricyclic antidepressants; Serotonin reuptake inhibitor; Drug-free

Weight gain is a common side-effect of several psychotropic drugs and may seriously limit treatment compliance (Pijl and Meinders 1996). Increases in weight occur in particular during treatment with tricyclic antidepressants (Berken et al. 1984) and the atypical neuroleptics clozapine and olanzapine (Brömel et al. 1998; Bustillo et

From the Max Planck Institute of Psychiatry, Munich, Germany. Address correspondence to: Thomas Pollmächer, M.D., Max Planck Institute of Psychiatry, Kraepelinstrasse 10, D-80804 Munich, Germany.

Received April 9, 1999; revised August 12, 1999; accepted January 3, 2000 . al. 1996; Kraus et al. 1999). Although the effects of these drugs on several neurotransmitter systems such as the serotonergic, dopaminergic, and histaminergic systems may contribute to weight gain, the underlying mechanisms have remained obscure (Pijl and Meinders 1996).

Recently, however, research on obesity and weight regulation has contributed new perspectives through the discovery of leptin, a protein hormone involved in weight regulation (Pelleymounter et al. 1995; for review see Auwerx and Staels 1998), and tumor necrosis factor- $\alpha$ (TNF- $\alpha)$, a cytokine with its soluble receptors as Janusfaced mediators of weight gain and weight loss (for review see Argiles et al. 1997). Leptin induces reduced food intake, and dysregulated leptin signaling is accompanied by obesity in animals and humans (for review see Auwerx and Staels 1998). Animals that are de- 
ficient in leptin or its receptor are obese and supplementation of this protein in leptin-deficient animals reverses obesity, supporting a pivotal role of leptin in the regulation of appetite and weight (Lee et al. 1996, Pelleymounter et al. 1995).

In humans, plasma levels of leptin are higher in obese people than in lean controls and decrease with weight loss, suggesting a less sensitive receptor system in obese people (Considine et al. 1996). In addition, the cytokine TNF- $\alpha$ and its soluble receptors sTNFR-p55 and sTNFR-p75 are associated with weight regulation. TNF- $\alpha$ was described in 1981 as the molecule responsible for the wasting syndrome in chronic diseases and was named cachectin (Kawakami and Cerami 1981); later, it was sequenced and named tumor necrosis factor- $\alpha$ (Old 1985). TNF- $\alpha$ in concert with its receptors, which are either bound to membranes of various cell types or are shed into circulation, act on protein, glucose and lipid metabolism (for review see Argiles et al. 1997). Circulating levels of TNF- $\alpha$ and its soluble receptors are increased in obese subjects compared to lean controls and decrease with weight loss (Dandona et al. 1998; Hauner et al. 1998). It has been hypothesized that decreased TNF- $\alpha$ receptor sensitivity might lead to a lack of body weight control and consequently to an increase in caloric intake (for review see Argiles et al. 1997). In addition, in vitro and some in vivo data suggest that the TNF- $\alpha$ system and leptin are linked together (Finck et al. 1998). Leptin with its class-I cytokine receptor modulates the cellular immune response, and inflammatory cytokines such as TNF- $\alpha$ liberate leptin from adipocytes (for review see Argiles et al. 1997; Auwerx and Staels 1998).

Psychotropic drugs that typically lead to weight gain, such as clozapine and olanzapine, have been shown to activate the TNF- $\alpha$ system and leptin by increasing plasma levels of these cytokines and soluble cytokine receptors (Brömel et al. 1998; Kraus et al. 1999; Pollmächer et al. 1996). Therefore, the induction of these multifunctional mediators might play a role in drug-induced changes of body weight.

In the present study, designed to further evaluate this hypothesis, we investigated the time course of body weight and circulating levels of cytokines in depressive inpatients during the first six weeks of treatment with two antidepressant drugs with known different impacts on body weight. We also studied a group of unmedicated inpatients to control for unspecific effects of hospitalization per se. We chose the selective serotonin reuptake inhibitor paroxetine that generally does not affect body weight (Pijl and Meinders 1996), and the tricyclic antidepressants amitriptyline or its major active metabolite nortriptyline (Kessel and Simpson 1995) that induce weight gain (Berken et al. 1984). We also measured tympanic temperature and did white blood cell counts because TNF- $\alpha$ is pyrogenic and has numerous hematological effects (for review see van der Poll and Lowry 1995). In addition, we took the opportunity to investigate soluble interleukin-2 receptor (sIL-2r) levels, which have been reported to be increased in patients with the diagnosis of major depression (Maes et al. 1995b) or schizophrenia (Gaughran et al. 1998). However, it has already been shown that psychotropic medication, such as clozapine (Pollmächer et al. 1995, 1996), and cigarette smoking (Pollmächer and Hinze-Selch 1998) can also induce sIL-2r plasma levels. In a cross-sectional investigation on antidepressive medication, no effect on circulating levels of sIL-2r was found (Maes et al. 1995a), but a systematic longitudinal study has not yet been published.

We hypothesized that treatment with amitriptyline or nortriptyline would induce weight gain and increase plasma levels of leptin, TNF- $\alpha$, and soluble TNF receptors, whereas treatment with paroxetine and drug-free treatment would not.

\section{METHODS}

\section{Patients}

Twenty-two inpatients meeting the DSM-IV diagnostic criteria (American Psychiatric Association 1994) for major depressive disorder or dysthymic disorder but not for bipolar disorder and 14 inpatients meeting the DSMIV diagnostic criteria for various other mental disorders, including anxiety disorders $(n=5)$, adjustment disorders $(n=3)$, schizophreniform disorder $(n=1)$, and personality disorders $(n=5)$, gave written informed consent before participating in this study, which had been approved by an independent ethics committee. None of the patients met the criteria for substance abuse or dependence, nor for any eating disorder.

Physical examination, medical history and baseline laboratory investigations (white blood cell count, differential counts, red blood cell count, creatinine, electrolytes, GOT, GPT, AP, $\gamma \mathrm{GT}$, Quick, partial thromboplastin time, serum electrophoresis, blood sedimentation rate, C-reactive protein, serum iron, transferrin, glucose, thyroid-stimulating hormone) did not reveal acute or chronic inflammation and infection or autoimmunological, endocrinological or hematological disease. Of the 22 patients with depressive or dysthymic disorder, 12 were medicated with amitriptyline $(n=9)$ or nortriptyline $(n=3)$ and 10 with paroxetine. The decision about which substance to administer was based on clinical considerations.

None of the patients had been treated during the preceding six months with the substance he/she was to receive during the present study. Six of the 12 patients to be treated with amitriptyline/nortriptyline were not psychopharmacologically treated during the preceding 
six months. In the remaining six patients, psychotropic medication included fluspirilene, maprotilene, moclobemide, oxazepam, diazepam, and valproic acid and was discontinued before the enrollment in the study except for valproic acid, which was continued as mood stabilizer in one patient. Four of the 10 patients to be treated with paroxetine had not taken any psychotropic substances during the preceding 6 months. In the remaining 6 patients psychotropic medication included haloperidol, chloral hydrate, lorazepam, carbamazepine and fluoxetine and was discontinued before enrollment in the study except for carbamazepine, which was continued as mood stabilizer in one patient. Of the 14 patients meeting the diagnostic criteria for various other mental disorders, eight had not been treated psychopharmacologically during the preceding six months. The remaining six patients had been given one of the following: diazepam, lorazepam, bromazepam, flupenthixol, fluspirilene, and trimipramine. Pharmacological treatment was discontinued before enrollment in the study and the patients remained drug-free during the six-week study period, and sometimes much longer, for purposes of clinical observation and diagnostic and therapeutic reevaluation. None of the 36 patients received additional psychotropic medication during the six weeks of the study.

\section{Experimental Procedure}

After the initial evaluation, medication was started and the dosage was adjusted according to clinical needs in the 22 inpatients with depressive or dysthymic disorder; the 14 inpatients with various other diagnoses were kept drug-free. White blood cell counts and differential counts were assessed weekly, tympanic temperature with rectal reference was screened daily in the evening (Genius $^{\mathrm{TM}}$, 3000A; Sherwood Medical GmbH, Sulzbach, Germany). Blood was drawn and the patients were weighed between 0800 and 0900 hours before the initiation of treatment and at the end of weeks 1, 2, 4, and 6 . Leukocyte, granulocyte, lymphocyte, and monocyte counts were assessed with a Coulter counter (Counter MAXM; Coulter Inc., Krefeld, Germany).

Blood for the determination of the cytokines and the soluble cytokine receptors was stabilized with sodium ethylenediaminetetraacetic acid $(1 \mathrm{mg} / \mathrm{ml})$ and aproti$\operatorname{nin}(300 \mathrm{kIU} / \mathrm{ml})$, immediately centrifuged and plasma was frozen to $-20^{\circ} \mathrm{C}$. Cytokines were measured with commercial enzyme-linked immunosorbent assays [TNF- $\alpha$, sTNFR-p55, sTNFR-p75 (Medgenix Diagnostics, Brussels, Belgium); sIL-2r (Biermann Diagnostics, Bad Nauheim, Germany)] or with a commercial radioimmunoassay [leptin (Linco Research, Missouri, USA)]. For all assays the intra- and inter-assay coefficients were below 7 and $9 \%$, respectively. Detection limits were $3 \mathrm{pg} / \mathrm{ml}$ for TNF- $\alpha, 50 \mathrm{pg} / \mathrm{ml}$ for sTNFR-p55, 100 $\mathrm{pg} / \mathrm{ml}$ for sTNFR-p75, $16 \mathrm{IU} / \mathrm{ml}$ for sIL-2r, and $0.5 \mathrm{ng} /$ $\mathrm{ml}$ for leptin. The body mass index (BMI) was calculated as BMI = body weight $[\mathrm{kg}] /$ height $[\mathrm{m}]^{2}$.

\section{Statistics}

Multivariate analysis of variance (MANOVA) for repeated measures was performed separately for each of the three treatment conditions to test for the effects of time. When a significant effect of time was found tests with simple contrasts were used to localize the timepoints differing significantly from baseline. Two-tailed Pearson's correlation coefficients were computed to investigate the relationship between the changes of BMI and body weight on the one hand and those of sTNFRp75 on the other hand from baseline to weeks 1 and 6 . Testing for baseline differences in age, body weight, BMI, and plasma levels of leptin, TNF- $\alpha$, sTNFR-p55, sTNFR-p75, and sIL-2r between the three treatment groups was performed by MANOVA and post hoc comparisons were done by tests with contrasts. The categorical variables were compared with the chi-square test.

Results are expressed and presented as means \pm standard deviation (SD). The nominal level of significance was set to $\alpha<0.05$ and corrected according to the Bonferroni procedure for all post hoc comparisons.

\section{RESULTS}

Table 1 shows that the patients treated with amitriptyline/nortriptyline were significantly older than those treated with paroxetine and the drug-free patients. The proportion of men and women and of smokers and nonsmokers did not differ significantly between groups. In both medicated patient groups, the dosage of the drug increased significantly from week 1 to week 6 and reached a mean dose that is considered to be clinically effective (see Tables 2 and 3 ).

MANOVA revealed a significant difference between groups with respect to the baseline BMI $(\mathrm{F}[3,32]=3.7, p<$ .05). This global difference was due to a significantly higher $\mathrm{BMI}$ in the amitriptyline/nortriptyline group (26.2 \pm 4.2 $\mathrm{kg} / \mathrm{m}^{2}$ ) compared to the drug-free control group (22.6 \pm $\left.2.6 \mathrm{~kg} / \mathrm{m}^{2}\right)$, whereas the baseline BMI in the paroxetine treated patients was intermediate $\left(23.7 \pm 4.1 \mathrm{~kg} / \mathrm{m}^{2}\right)$ and did not differ significantly from any of the other two groups. There were no significant differences between groups at baseline with respect to body weight, and the plasma levels of leptin, TNF- $\alpha$, sTNFR-p55, sTNFR-p75, and sIL-2r (data not shown).

When the longitudinal effect of the three treatment conditions on the variables was tested, MANOVA revealed no significant time effects in the patients treated with paroxetine or in the unmedicated patients (Tables 3 and 4). In the patients treated with amitriptyline/nortriptyline (Table 2), however, plasma levels of sTNFR-p75 
Table 1. Demographic Data by Treatment

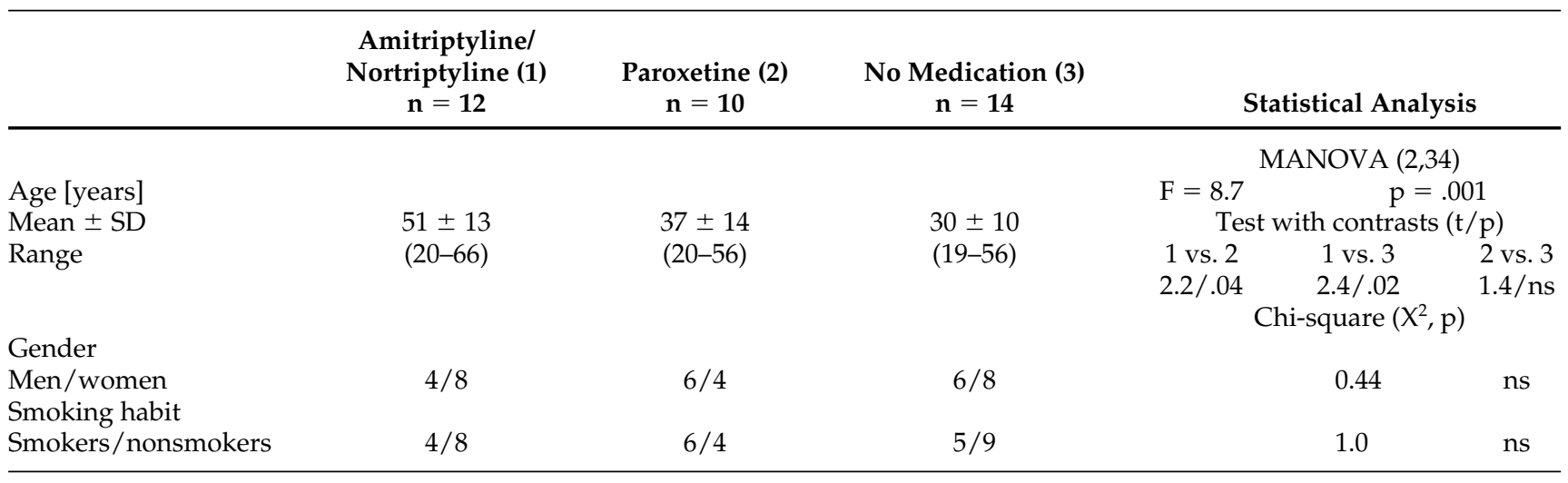

were significantly higher at weeks $1,2,4$, and 6 compared to baseline, and plasma levels of sTNFR-p55 and TNF- $\alpha$ showed a tendency to increase over time. The increase in BMI and body weight occurred at week 6; the absolute and relative amounts of weight change at week 6 compared to baseline varied between $-1.8 \mathrm{~kg}$ and $+5.8 \mathrm{~kg}$ (mean \pm SD: $1.3 \pm 2.5 \mathrm{~kg}$ ) and $-2 \%$ and $+7 \%(2 \pm 4 \%)$, respectively. Plasma levels of leptin were not significantly affected (Table 2). Correlational analysis between the changes in the plasma levels of sTNFR-p75 from baseline to week 1 and week 6 , and the changes in weight and BMI in the respective time periods did not reveal any significant associations (data not shown). In none of the three treatment conditions did time have a significant effect on the plasma levels of sIL-2r (Tables 2, 3, and 4), on blood cell counts or on tympanic temperature (data not shown).

\section{DISCUSSION}

The present study is the first to assess the longitudinal effects of drug-free inpatient treatment and treatment with different antidepressants on both body weight and the plasma levels of cytokines. We investigated the effects of amitriptyline and its major active metabolite nortriptyline, which are known to induce weight gain (Berken et al. 1984), and of paroxetine, which typically does not affect body weight (Pijl and Meinders 1996). We also included a group of unmedicated psychiatric inpatients because it has not yet been clarified whether or not inpatient treatment per se leads to changes in body weight and plasma levels of cytokines. As the atypical neuroleptics clozapine and olanzapine (Kraus et al. 1999; Pollmächer et al. 1996) lead to weight gain and induce leptin and the TNF- $\alpha$-system, which are known to be involved in weight regulation (for review see Auwerx and Staels 1998; Argiles et al. 1997), we expected the tricyclic antidepressants to have similar effects, and we hypothesized that neither the selective serotonin reuptake inhibitor paroxetine nor drug-free inpatient treatment would affect these variables.

Indeed, we found that drug-free inpatient treatment and treatment with paroxetine did not have any effect on weight, BMI, or plasma levels of leptin, TNF- $\alpha$, sTNFRp55, or sTNFR-p75. However, the effects of the tricyclic antidepressants observed are not completely in line with our hypothesis. Although the patients treated with amitrip-

Table 2. Effects of Amitriptyline/Nortriptyline on Body Weight, BMI, and on Plasma Levels of Cytokines and Their Soluble Receptors, $n=12$

\begin{tabular}{|c|c|c|c|c|c|c|c|c|}
\hline & \multirow[b]{2}{*}{ Baseline } & \multirow[b]{2}{*}{ Week 1} & \multirow[b]{2}{*}{ Week 2} & \multirow[b]{2}{*}{ Week 4} & \multirow[b]{2}{*}{ Week 6} & \multicolumn{3}{|c|}{ MANOVA } \\
\hline & & & & & & df & $\mathbf{F}$ & $p$ \\
\hline Dosage $[\mathrm{mg} / \mathrm{d}]$ & $0 \pm 0$ & $92 \pm 50$ & $127 \pm 38^{*}$ & $134 \pm 38^{*}$ & $142 \pm 34^{*}$ & 3,33 & 5.3 & .000 \\
\hline $\mathrm{TNF}-\alpha[\mathrm{pg} / \mathrm{ml}]$ & $12.0 \pm 3.0$ & $12.7 \pm 3.8$ & $12.8 \pm 2.3$ & $13.9 \pm 2.9$ & $14.5 \pm 3.6$ & 4,44 & 2.0 & ns \\
\hline STNFR-p55 [ng/ml] & $1.73 \pm 0.43$ & $1.76 \pm 0.49$ & $1.86 \pm 0.46$ & $1.88 \pm 0.55$ & $1.94 \pm 0.66$ & 4,44 & 2.0 & ns \\
\hline STNFR-p75 [ng/ml] & $4.69 \pm 1.35$ & $5.03 \pm 1.21^{*}$ & $5.05 \pm 0.94^{*}$ & $5.32 \pm 1.22^{*}$ & $5.54 \pm 1.34^{*}$ & 4,44 & 5.6 & .001 \\
\hline SIL-2r $[\mathrm{U} / \mathrm{ml}]$ & $298 \pm 149$ & $282 \pm 101$ & $297 \pm 119$ & $320 \pm 120$ & $340 \pm 152$ & 4,44 & 1.6 & ns \\
\hline Leptin $[\mathrm{ng} / \mathrm{ml}]$ & $17.0 \pm 13.8$ & $14.6 \pm 9.9$ & $15.0 \pm 12.2$ & $15.0 \pm 11.0$ & $15.6 \pm 12.8$ & 4,44 & 0.9 & ns \\
\hline BMI $\left[\mathrm{kg} / \mathrm{m}^{2}\right]$ & $26.22 \pm 4.20$ & $26.31 \pm 4.20$ & $26.31 \pm 4.22$ & $26.50 \pm 4.08$ & $26.84 \pm 2.11^{*}$ & 4,44 & 4.0 & .01 \\
\hline Body weight $[\mathrm{kg}]$ & $75.0 \pm 11.5$ & $75.3 \pm 11.6$ & $75.3 \pm 11.9$ & $75.9 \pm 11.6$ & $78.5 \pm 10.4^{*}$ & 4,44 & 4.7 & .003 \\
\hline
\end{tabular}

Post-hoc comparisons were done by tests with contrasts referring to baseline; ${ }^{*} p<.05$; means \pm SD. 
Table 3. Effects of Paroxetine on Body Weight, BMI, and on Plasma Levels of Cytokines and Their Soluble Receptors, $n=10$

\begin{tabular}{|c|c|c|c|c|c|c|c|c|}
\hline & \multirow[b]{2}{*}{ Baseline } & \multirow[b]{2}{*}{ Week 1} & \multirow[b]{2}{*}{ Week 2} & \multirow[b]{2}{*}{ Week 4} & \multirow[b]{2}{*}{ Week 6} & \multicolumn{3}{|c|}{ MANOVA } \\
\hline & & & & & & df & $\mathbf{F}$ & $p$ \\
\hline Dosage $[\mathrm{mg} / \mathrm{d}]$ & $0 \pm 0$ & $17 \pm 5$ & $22 \pm 11^{*}$ & $28 \pm 12^{*}$ & $35 \pm 11^{*}$ & 3,27 & 6.2 & .001 \\
\hline TNF- $\alpha[\mathrm{pg} / \mathrm{ml}]$ & $11.1 \pm 4.9$ & $10.0 \pm 5.5$ & $10.0 \pm 5.4$ & $11.7 \pm 3.9$ & $11.8 \pm 4.4$ & 4,36 & 0.8 & ns \\
\hline STNFR-p55 [ng/ml] & $1.56 \pm 0.25$ & $1.59 \pm 0.20$ & $1.55 \pm 0.21$ & $1.60 \pm 0.22$ & $1.65 \pm 0.34$ & 4,36 & 0.9 & ns \\
\hline STNFR-p75 [ng/ml] & $4.40 \pm 0.94$ & $4.60 \pm 1.16$ & $4.43 \pm 0.92$ & $4.57 \pm 1.03$ & $4.73 \pm 0.99$ & 4,36 & 0.9 & ns \\
\hline SIL-2r [U / $\mathrm{ml}]$ & $202 \pm 103$ & $203 \pm 82$ & $198 \pm 77$ & $201 \pm 94$ & $208 \pm 102$ & 4,36 & 0.1 & ns \\
\hline Leptin [ng/ml] & $7.2 \pm 5.9$ & $5.7 \pm 4.2$ & $6.3 \pm 5.1$ & $6.6 \pm 3.7$ & $6.6 \pm 3.2$ & 4,36 & 0.7 & ns \\
\hline $\mathrm{BMI}\left[\mathrm{kg} / \mathrm{m}^{2}\right]$ & $23.68 \pm 4.05$ & $23.68 \pm 4.06$ & $23.72 \pm 3.97$ & $23.97 \pm 3.77$ & $24.01 \pm 3.79$ & 4,32 & 0.7 & ns \\
\hline Body weight $[\mathrm{kg}]$ & $72.9 \pm 16.1$ & $73.1 \pm 16.0$ & $73.2 \pm 16.0$ & $73.8 \pm 15.6$ & $73.9 \pm 16.9$ & 4,32 & 0.6 & ns \\
\hline
\end{tabular}

Reported are means \pm SD.

tyline/nortripyline had a significant weight gain over time, only the circulating levels of sTNFR-p75 increased significantly and the plasma levels of TNF- $\alpha$ and sTNFRp55 showed a tendency to increase. Unexpectedly, the tricyclic antidepressants did not affect plasma levels of leptin.

Already at week 1 of treatment and persisting until week 6 , there were significant increases in the circulating levels of sTNFR-p75, which is the most sensitive parameter of the TNF- $\alpha$ system in association with weight change (Hauner et al. 1998). To our knowledge, the present study is the first to investigate prospectively the temporal relationship between changes in weight and in circulating levels of sTNFR-p75. As the effects on sTNFR-p75 preceded the increase in the BMI, our data suggest that weight gain might be a consequence of an induction of the TNF- $\alpha$ system. Therefore, the ability of a psychoactive substance to induce the TNF- $\alpha$ system might be a predictor for weight gain in the course of treatment. However, as statistical analysis did not reveal any significant correlations between the increases in weight and BMI and the increases in sTNFR-p75 plasma levels such proposed association might be more complex than a simply linear relationship.
As the patient groups investigated in this study were not matched for body weight and BMI, and the patients treated with amitriptyline or nortriptyline had higher BMI values than the control patients at baseline, we can not exclude that these baseline conditions might be at least additional requirements for the tricyclic antidepressants to induce weight gain. To our knowledge, the effect of pretreatment weight and BMI on any changes induced by antidepressant medication has not yet been investigated. However, for antipsychotic treatment it has recently been shown that, if there is any relationship between baseline weight and weight gain during treatment, it is lower baseline weight that predisposes to weight gain (Wetterling and Mussigbrodt 1999). To summarize, it seems unlikely that the baseline BMI in patients to be treated with the tricyclics that was higher than the baseline BMI in the patients to remain unmedicated and comparable to the baseline BMI in the patients to be treated with paroxetine plays a major role in the weight gain and increase in sTNFR-p75 plasma levels we have seen during tricyclic antidepressant treatment. However, further studies are needed to systematically address the issue of whether or not pretreatment

Table 4. Effects of Drug-Free Inpatient Treatment on Body Weight, BMI, and on Plasma Levels of Cytokines and Their Soluble Receptors, $n=14$

\begin{tabular}{|c|c|c|c|c|c|c|c|c|}
\hline & \multirow[b]{2}{*}{ Baseline } & \multirow[b]{2}{*}{ Week 1} & \multirow[b]{2}{*}{ Week 2} & \multirow[b]{2}{*}{ Week 4} & \multirow[b]{2}{*}{ Week 6} & \multicolumn{3}{|c|}{ MANOVA } \\
\hline & & & & & & df & $\mathbf{F}$ & $p$ \\
\hline $\mathrm{TNF}-\alpha[\mathrm{pg} / \mathrm{ml}]$ & $14.1 \pm 3.3$ & $14.0 \pm 3.9$ & $13.9 \pm 2.7$ & $13.9 \pm 4.1$ & $14.6 \pm 3.0$ & 4,52 & 0.2 & ns \\
\hline STNFR-p55 [ng/ml] & $1.56 \pm 0.33$ & $1.56 \pm 0.36$ & $1.56 \pm 0.34$ & $1.58 \pm 0.34$ & $1.57 \pm 0.33$ & 4,52 & 0.1 & ns \\
\hline STNFR-p75 [ng/ml] & $4.52 \pm 0.99$ & $4.44 \pm 0.93$ & $4.54 \pm 0.96$ & $4.48 \pm 1.06$ & $4.59 \pm 1.13$ & 4,52 & 0.2 & ns \\
\hline SIL-2r [U / ml] & $224 \pm 73$ & $228 \pm 68$ & $238 \pm 68$ & $288 \pm 94$ & $240 \pm 63$ & 4,52 & 2.1 & ns \\
\hline Leptin $[\mathrm{ng} / \mathrm{ml}]$ & $8.6 \pm 6.5$ & $8.4 \pm 6.6$ & $8.0 \pm 5.6$ & $7.3 \pm 4.4$ & $7.8 \pm 5.5$ & 4,52 & 0.6 & ns \\
\hline $\mathrm{BMI}\left[\mathrm{kg} / \mathrm{m}^{2}\right]$ & $22.57 \pm 2.58$ & $22.63 \pm 2.47$ & $22.55 \pm 2.44$ & $22.51 \pm 2.32$ & $22.48 \pm 2.39$ & 4,52 & 0.7 & ns \\
\hline Body weight $[\mathrm{kg}]$ & $66.1 \pm 10.4$ & $66.3 \pm 10.4$ & $66.1 \pm 10.3$ & $66.0 \pm 10.2$ & $65.9 \pm 10.1$ & 4,52 & 0.4 & $\mathrm{~ns}$ \\
\hline
\end{tabular}

Reported are means \pm SD. 
conditions such as body weight, BMI, and the nutritional status affect longitudinal effects of antidepressant treatment.

The mechanisms underlying the phenomenon of increased circulating levels of TNF- $\alpha$, soluble TNF receptors, and leptin in obesity are still unclear. However, there are two main routes by which psychotropic drugs such as amitriptyline and nortriptyline could interfere with these systems. They could induce increased plasma levels of sTNFR-p75 directly by shedding this receptor from cell surfaces. This would lead to a dysregulated TNF- $\alpha$ system as the starting point for dysregulated caloric intake and metabolism. Alternatively, the increase in sTNFR-p75 plasma levels could be part of a cascade of reactions initiated by the drugs, and the observed alteration of the TNF- $\alpha$ system would then be the consequence of effects on the metabolic system. Both options allow for additional involvement of central and peripheral neurotransmitters such as serotonin, adrenalin, noradrenalin, and histamine which were shown to be linked with the TNF- $\alpha$ system (Chou et al. 1996; Clement et al. 1997; Kawashima et al. 1998; for review see Müller and Ackenheil 1998).

In the present study, we also investigated the plasma levels of sIL-2r, body temperature, and blood cell counts in the course of drug-free and antidepressant inpatient treatment. It had been shown previously that the atypical neuroleptic clozapine affects all of these variables (Pollmächer et al. 1995, 1996), and it had been postulated that the diagnosis of depression might be associated with increased circulating levels of sIL-2r (Maes et al. 1995b). We found that amitriptyline, nortriptyline, paroxetine, and drug-free inpatient treatment all had no significant effect on any of these parameters. Thus, elevated plasma levels of sIL-2r in patients with major depression are unlikely to be caused by the antidepressants mentioned or by inpatient treatment per se.

To summarize, the present study together with recent data on clozapine (Pollmächer et al. 1996) demonstrate that certain psychotropic drugs activate the TNF- $\alpha$ system prior to significant weight gain, whereas other drugs such as paroxetine and haloperidol (Kraus et al. 1999; Pollmächer et al. 1997) as well as drug-free inpatient treatment do neither activate the TNF- $\alpha$ system nor induce weight gain. Therefore, we suggest two major conclusions: 1) weight gain induced by psychotropic agents is not necessarily accompanied by an increase in circulating levels of leptin; and 2) activation of the TNF- $\alpha$ system by psychotropic drugs may provide a major clue to the mechanism underlying weight gain in the course of psychotropic treatment. As the present study was not randomized or blinded, nor controlled for pharmacological pretreatment, further controlled studies are needed to substantiate the involvement of the TNF- $\alpha$ system in weight regulation during treatment with psychotropic drugs.

\section{REFERENCES}

American Psychiatric Association (1994): Diagnostic and Statistical Manual of Mental Disorders, 4th ed. Washington, DC, American Psychiatric Press

Argiles JM, Lopez-Soriano J, Busquets S, Lopez-Soriano FJ (1997): Journey from cachexia to obesity by TNF. FASEB 11:743-751

Auwerx J, Staels B (1998): Leptin. Lancet 351:737-742

Berken GH, Weinstein DO, Stern WC (1984): Weight gain: A side-effect of tricyclic antidepressants. J Affect Disord 7:133-138

Brömel T, Blum WF, Ziegler A, Schulz E, Bender M, Fleischhaker C, Remschmidt H, Krieg JC, Hebebrand (1998): Serum leptin levels increase rapidly after initiation of clozapine treatment. Mol Psychiatry 3:76-80

Bustillo JR, Buchanan RW, Breier ID (1996): Differential effect of clozapine on weight: A controlled study. Am J Psychiatry 153:817-819

Chou RC, Stinson MW, Noble BK, Spengler RN (1996): Betaadrenergic receptor regulation of macrophage-derived tumor necrosis factor-alpha production from rats with experimental arthritis. J Neuroimmunol 67:7-16

Clement HW, Buschmann J, Rex S, Grote C, Opper C, Gemsa D, Wesemann W (1997): Effects of interferon-gamma, interleukin-1 beta, and tumor necrosis factor-alpha on the serotonin metabolism in the nucleus raphe dorsalis of the rat. J Neural Transm 104:981-991

Considine RV, Sinha MK, Heiman ML, Kriauciunas A, Stephens TW, Nyce MR, Ohannessian JP, Marco CC, McKee LJ, Bauer TL, Caro JF (1996): Serum immunoreactive-leptin concentrations in normal-weight and obese humans. N Engl J Med 334:292-295

Dandona P, Weinstock R, Thusu K, Abdel-Rahman E, Aljada A, Wadden T (1998): Tumor necrosis factor- $\alpha$ in sera of obese patients: Fall with weight loss. J Clin Endocrinol Metab 83:2907-2910

Finck BN, Kelley KW, Dantzer R, Johnson RW (1998): In vivo and in vitro evidence for the involvement of tumor necrosis factor- $\alpha$ in the induction of leptin by lipopolysaccharide. Endocrinology 139:2278-2283

Gaughran F, O'Neill E, Cole M, Collins K, Daly RJ, Shanahan F (1998): Increased soluble interleukin-2 receptor levels in schizophrenia. Schizophr Res 29:263-267

Hauner H, Bender M, Haastert B, Hube F (1998): Plasma concentrations of soluble TNF-alpha receptors in obese subjects. Int J Obes 22:1239-1243

Kawakami M, Cerami A (1981): Studies of endotoxininduced decrease in lipoprotein lipase activity. J Exp Med 154:631-639

Kawashima S, Hayashi M, Takii T, Kimura H, Zhang HL, Nagatsu A, Sakakibara J, Murata K, Oomoto Y, Onozaki K (1998): Serotonin derivative, N-(p-coumaroyl) serotonin, inhibits the production of TNF-alpha, IL-1alpha, IL-1beta, and IL-6 by endotoxin-stimulated human blood monocytes. J Interfer Cytok Res 18:423-428

Kessel JB, Simpson GM (1995): Biological therapies: Tricyclic and tetracyclic drugs. In Kaplan HI, Sadock BJ (eds), Comprehensive Textbook of Psychiatry. IV. 6th ed. Baltimore, MD, Williams \& Wilkins, pp 2099 
Kraus T, Haack M, Schuld A, Hinze-Selch D, Kühn M, Uhr M, Pollmächer T (1999): Body weight and leptin plasma levels during treatment with antipsychotic drugs. Am J Psychiatry 156:312-314

Lee GH, Proenca R, Montez JM, Carroll KM, Darvishzadeh JG, Lee JI, Friedman JM (1996): Abnormal splicing of the leptin receptor in diabetic mice. Nature 279:632-635

Maes M, Meltzer HY, Bosmans E, Bergmans R, Vandoolaeghe E, Ranjan R, Desnyder R (1995a): Increased plasma concentrations of interleukin-6, soluble interleukin-6, soluble interleukin-2 and transferrin receptor in major depression. J Affective Disord 34:301-309

Maes M, Meltzer HY, Buckley P, Bosmans E (1995b): Plasma soluble interleukin-2 and transferrin receptor in schizophrenia and depression. Eur Arch Psychiatry Clin Sci 244:325-329

Müller N, Ackenheil M (1998): Psychoneuroimmunology and the cytokine action in the CNS: Implications for psychiatric disorders. Prog Neuropsychopharmacol Biol Psychiatry 22:1-33

Old LJ (1985): Tumor necrosis factor (TNF). Science 230:630-632

Pelleymounter MA, Cullen MJ, Baker MB, Hecht R, Winters D, Boone T, Collins F (1995): Effects of the obese gene product on body weight regulation in ob/ob mice. Science 269:540-543

Pijl H, Meinders E (1996): Bodyweight change as an adverse effect of drug treatment: Mechanisms and management. Drug Safety 14:329-342

Pollmächer T, Hinze-Selch D (1998): Factors confounding studies of circulating soluble interleukin-2 receptor levels in schizophrenia. Schizophr Res 33:123-124

Pollmächer T, Hinze-Selch D, Fenzel T, Kraus T, Schuld A, Mullington J (1997): Plasma levels of cytokines and soluble cytokine receptors during treatment with haloperidol. Am J Psychiatry 154:1763-1765

Pollmächer T, Hinze-Selch D, Mullington J (1996): Effects of clozapine on cytokines and soluble cytokine receptors. J Clin Psychopharmacol 16:403-409

Pollmächer T, Hinze-Selch D, Mullington J, Holsboer F (1995): Clozapine-induced increase in plasma levels of soluble interleukin-2 receptors. Arch Gen Psychiatry 52:877-878

van der Poll T, Lowry SF (1995): Tumor necrosis factor in sepsis: Mediator of multiple organ failure or essential part of host defense? Shock 3:1-12

Wetterling T, Mussigbrodt HE (1999): Weight gain: Side effect of atypical neuroleptics? J Clin Psychopharmacol 19:312-316 